\title{
Dissolving Hydroxyolite: A DNA Molecule into Its Hydroxyapatite Mold
}

\author{
Oscar Bertran, ${ }^{[a]}$ Guillermo Revilla-López,${ }^{[b]}$ Jordi Casanovas, ${ }^{[c]}$ Luis J. del Valle, ${ }^{[b, d]}$ Pau Turon, ${ }^{* e]}$ Jordi \\ Puiggalí, ${ }^{*[\mathrm{~b}, \mathrm{~d}]}$ and Carlos Alemán*[b,d]
}

\begin{abstract}
In spite of the clinical importance of hydroxyapatite (HAp), the mechanism that controls its dissolution in acidic environments remains unclear. Knowledge of such process is highly desirable to provide better understanding of different pathologies, as for example osteoporosis, and of the HAp potential as vehicle for gene delivery to replace damaged DNA. In this work, the mechanism of dissolution in acid conditions of HAp nanoparticles encapsulating double-stranded DNA has been investigated at the atomistic level using computer simulations. For this purpose, four consecutive (multi-step) molecular dynamics simulations, involving different temperatures and proton transfer processes, have been carried out. Results are consistent with a polynuclear decalcification mechanism in which proton transfer processes, from the surface to the internal regions of the particle, play a crucial role. Besides, the DNA remains protected by the mineral mold and transferred proton from both temperature and chemicals. These results, which indicate that biomineralization imparts very effective protection to DNA, also have important implications in other biomedical fields, as for example in the design of artificial bones or in the fight against osteoporosis by promoting the fixation of $\mathrm{Ca}^{2+}$ ions.
\end{abstract}

\section{Introduction}

Biomineralization is about the formation of inorganic materials in a biological environment. Certain biominerals composed of calcium phosphate (microcalcifications) are associated with pathogeneses of tissues such breast cancers, osteoarthritis and vascular calcifications. ${ }^{[1]}$ Currently, demineralization of double-

[a] Dr. O. Bertran

Departament de Física Aplicada, EEI, Universitat Politècnica de Catalunya, Av. Pla de la Massa, 8, 08700 Igualada, Spain

[b] Dr. G. Revilla-López, Dr. L. J. del Valle, Prof. Dr. J. Puiggalí, Prof. Dr. C. Alemán

Departament d'Enginyeria Química, ETSEIB, Universitat Politècnica de Catalunya, Diagonal 647, 08028 Barcelona, Spain

E-mail: jordi.puiggali@upc.edu and carlos.aleman@upc.edu

[c] Dr. J. Casanovas

Departament de Química, EPS, Universitat de Lleida, c/ Jaume II no 69, Lleida E-25001, Spain

[d] Dr. L. J. del Valle, Prof. Dr. J. Puiggalí, Prof. Dr. C. Alemán Center for Research in Nano-Engineering, Universitat Politècnica de Catalunya, Campus Sud, Edifici C', C/Pasqual i Vila s/n, Barcelona E-08028, Spain

[d] Dr. P. Turon

B. Braun Surgical, S.A. Carretera de Terrasa 121, 08191 Rubí

(Barcelona), Spain

E-mail: pau.turon@bbraun.com

Supporting information for this article is given via a link at the end of the document stranded DNA (ds-DNA) with hydroxyapatite (HAp) is at the forefront of the emerging clinical and medical applications (gene therapy) because its importance in the development of controlled vehicles for gene delivery to replace damaged DNA. In addition, clinical observations have evidenced that bone HAp dissolution in acid environments is directly related with the pathophysiology of cancer-associated bone pain and osteoporosis, even though their mechanisms remain poorly understood. ${ }^{[2]}$ Bioactive particles made of DNA encapsulated and protected by HAp, recently named hydroxyolites (HOli), ${ }^{[3]}$ exhibit good cell absorption, significant transfection efficiency and high biocompatibility. They are obtained by covering genetic material with $\mathrm{HAp}^{[4]}$ Dissolution of HOli is worth being studied because is directly related to the transfection efficiency and, additionally, it has been related with relevant life events on Earth since HOlis might release protected information encoded in DNA under certain conditions. ${ }^{[3]}$

In recent years the formation mechanism of HAp biominerals on ds-DNA soft templates has been investigated and characterized. ${ }^{[5-8]}$ Nevertheless, the molecular mechanism that drives the particle dissolution and DNA demineralization remains widely unknown and controversial. ${ }^{[9-11]}$ In this work we use a four-step approach based on atomistic molecular dynamics (MD) simulations to clarify the dissolution mechanism of HOli in acid environments, mimicking the physiological $\mathrm{pH}$ variations of the intracellular fluid encountered inside the cell cytosol and nucleus.

\section{Construction of the molecular Model}

The model for the biomineral was constructed considering the following experimental observations: (i) carbonate and $\mathrm{Mg}^{2+}$ substitution in HAp, extensively observed in living organisms, may increase its solubility; ${ }^{[6-8]}$ and (ii) the solubility also increases with decreasing crystallinity. ${ }^{[12]}$ Initially, a HAp nanoparticle of composition similar to that found in previous exnerimental studies ${ }^{[6]}$ was constructed using $\mathrm{Ca}^{2+}, \mathrm{Mg}^{2+}, \mathrm{OH}^{-}$, $\mathrm{PO}_{4}^{3-}$ and $\mathrm{CO}_{3}^{2-}$ ions. For this purpose, we used as starting point one of the small aggregates obtained in a previous work, ${ }^{[6]}$ which was spontaneously formed in neutral water from a bulk solution of the same ions. The rest of the ions were slowly added using the following strategy: (i) a randomly chosen ion was placed at a position randomly chosen among all those that are within a distance $d$, with $5 \AA<d<10 \AA$, from any atom located at the surface of the nanoparticle; (ii) the added ion was integrated in the nanoparticle through energy minimization.

After this, the Dickerson's dodecamer (5'-CGCGAATTCGCG-3'), which is a well-known sequence that adopts a B-DNA double helix, ${ }^{[13]}$ was placed in the center of such nanoparticle, ions 
overlapping any atom of the ds-DNA being subsequently removed. In order to maintain the electrical neutrality of the system, $\mathrm{Ca}^{2+}$ ions were put at the minor groove of the double helix, as is frequently observed by X-ray diffraction. ${ }^{[14,15]}$ The charge of the whole biomineral was neutralized by removing ions from the external surface (i.e. the final charge of the dsDNA and the HAp nanocapsule was -20 and +20 , respectively). Next, the HOli nanoparticle was immersed in a water box of $130 \times 130 \times 130 \AA^{3}$ and the solvent molecules overlapping any atom of the mineral were removed. Finally, 1000 water molecules were transformed into $\mathrm{H}_{3} \mathrm{O}^{+}$, which were neutralized with $\mathrm{Cl}^{-}$ions put at relatively close sterically accessible positions, to mimic the acidic conditions. Obviously, the $\mathrm{pH}$ of the medium is very low with such high number of $\mathrm{H}_{3} \mathrm{O}^{+}$cations. However, it should be noted that approaches based on much higher concentrations in simulations, relative to the experiment, are frequently considered to allow events to occur on a shorter timelength scale. The resulting mineral mold, which contained 656 $\mathrm{Ca}^{2+}, 42 \mathrm{Mg}^{2+}, 112 \mathrm{OH}^{-}, 412 \mathrm{PO}_{4}^{3-}, 14 \mathrm{CO}_{3}^{2-}$ ions, was surrounded by 50552 water molecules, $1000 \mathrm{H}_{3} \mathrm{O}^{+}$and $1000 \mathrm{Cl}^{-}$. The total number of explicit atoms, including ds-DNA, was 160,328 .

Two independent molecular models were constructed using this strategy since the study was performed using two sets of independent MD simulations. Although results discussed in this work correspond to one of such sets only, similar observation were obtaioned from the second set, giving consistency to their interpretation and discussion.

\section{Results and Discussion}

Equilibration at $298 \mathrm{~K}$ and 1 bar (Figure 1a) was performed following the MD protocols described in the Methods section. The dissolution of the HOli was followed through changes in the $\mathrm{Ca}^{2+}$ distribution using two parameters: (i) the partial radial distribution function of $\mathrm{Ca}^{2+} \ldots \mathrm{Ca}^{2+}$ pairs, $g_{\mathrm{CaCa}}$, which is not expected to detect the first stages of dissolution process; and (ii) a $\rho(L)-L$ profile, where $\rho(L)=656 / \mathrm{M}(L), 656$ is the total number of $\mathrm{Ca}^{2+}$ ions in the model, $L$ is the edge of the identical cubes in which the simulation box was divided and $\mathrm{M}(L)$ is the number of cubes of edge $L$ containing at least one $\mathrm{Ca}^{2+}$. Accordingly, $\rho(L)$ defines the average number of $\mathrm{Ca}^{2+}$ per occupied cube of edge $L$, the shape of the $\rho(L)-L$ profile being very sensitive to the migration of ions from the initial nanopaticle to the bulk solution. The distribution of the $\mathrm{Ca}^{2+}$ in equilibrated HOli is described in Figure 2.

The equilibrated HOli was the starting point of the first MD run (MD1), which corresponded to $300 \mathrm{~ns}$ of NPT MD at $298 \mathrm{~K}$ and 1 bar pressure. After this, both the $\mathrm{g}_{\mathrm{CaCa}}$ and $\rho(\mathrm{L})-\mathrm{L}$ profiles remained practically unchanged (Figure $\mathrm{S} 1$ ), evidencing that the dissolution process did not start yet. Then, temperature was slowly increased to $320 \mathrm{~K}$, a production run of 200 ns being subsequently conducted (MD2). The $\mathrm{g}_{\mathrm{CaCa}}$ profile calculated for the last snapshot was again identical to that of the equilibrated HOli, while the $\rho(L)$-L profile exhibited some differences (Figure S2). However, careful analysis of the results evidenced that such variations were not due to the migration of ions but to a change in the volume of the biomineral. Similar features were obtained when the temperature was slowly increased from 320 $\mathrm{K}$ to $350 \mathrm{~K}$ and a production run of $20 \mathrm{~ns}$ (MD3) was conducted (Figure 2). Accordingly, the nanoparticle underwent small rearrangements produced by a thermal expansion, which resulted in a variation in the corresponding $\rho(L)-L$ curve. More specifically, the volume of the nanoparticle increased from $86368 \AA^{3}$ at $298 \mathrm{~K}$ to $88436(2.4 \%)$ and $88509 \AA^{3}(2.5 \%)$ at 320 and $350 \mathrm{~K}$, respectively.

(a)
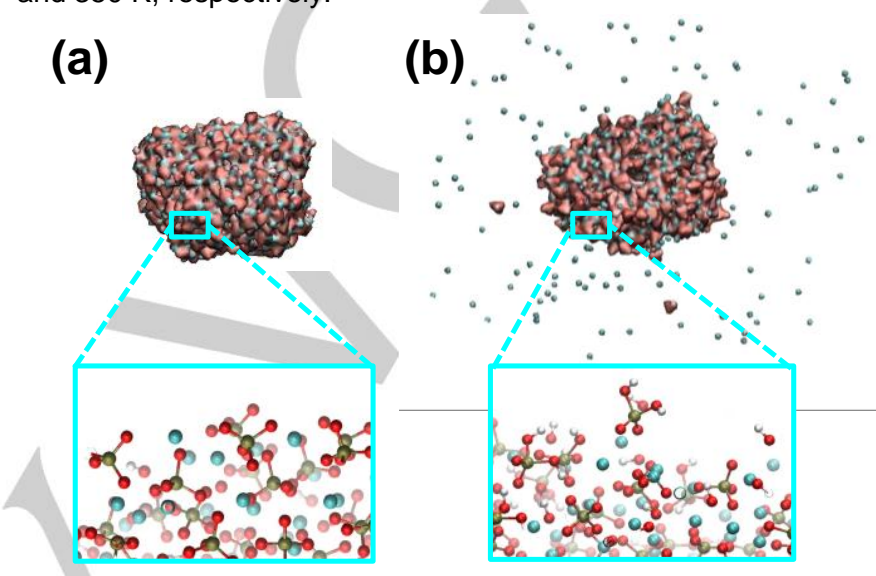

Figure 1. HOli nanoparticle (a) after equilibration and (b) after multi-step MD simulation (last snapshot). The distribution of the ions at the surface is illustrated in the magnifications. Brown, red, light grey, and blue balls represent $\mathrm{P}, \mathrm{O}, \mathrm{H}$ and $\mathrm{Ca}$, respectively.

The solubility of HAp in acid environments is known to increase with temperature. ${ }^{[16]}$ However, simulations indicate that the description of the interactions at the nanoparticle/bulk interface is not enough to promote the HOli dissolution, independently of the temperature. The influence of the acidic conditions was introduced in the mechanism by considering reactions (1) and (2) in the next MD step:

$$
\begin{aligned}
& \mathrm{PO}_{4}^{3-}+\mathrm{H}_{3} \mathrm{O}^{+} \rightarrow \mathrm{HPO}_{4}^{2-}+\mathrm{H}_{2} \mathrm{O} \\
& \mathrm{HPO}_{4}^{2-}+\mathrm{H}_{3} \mathrm{O}^{+} \rightarrow \mathrm{H}_{2} \mathrm{PO}_{4}^{-}+\mathrm{H}_{2} \mathrm{O}
\end{aligned}
$$

These reactions were incorporated into the protocol considering variations in composition at time steps $\Delta t$. Specifically, the following changes were considered: a $\mathrm{PO}_{4}^{3-}$ (or $\mathrm{HPO}_{4}^{2-}$ ) located at the HOli surface and a $\mathrm{PO}_{4}^{3-}$ from the solution separated by less than $3 \AA$ were replaced by $\mathrm{HPO}_{4}^{2-}$ (or $\mathrm{H}_{2} \mathrm{PO}_{4}^{-}$) and $\mathrm{H}_{2} \mathrm{O}$, respectively. For each change, a new $\mathrm{H}_{3} \mathrm{O}^{+}$ . $\mathrm{Cl}^{-}$pair was inserted at one of the boundaries of the simulation box to maintain the initial acidic conditions. After several trials, the time step $\Delta t$ was fixed at $10 \mathrm{~ns}$, this value providing a reasonable ratio between success and failures in the fulfilment of the above mentioned distance requirement. In order to avoid the overconcentration of $\mathrm{HPO}_{4}^{2-}$ and $\mathrm{H}_{2} \mathrm{PO}_{4}^{-}$at the HOli surface as well as to mimic the proton transfer process experimentally observed in $\mathrm{HAp},{ }^{[17]}$ every five time steps, $5 \Delta t=$ $50 \mathrm{~ns}$, the conversion of an internal $\mathrm{PO}_{4}^{3-}$ (or $\mathrm{H}_{2} \mathrm{PO}_{4}^{-}$) into 
$\mathrm{HPO}_{4}^{2-}$ (or $\mathrm{H}_{2} \mathrm{PO}_{4}^{-}$) was considered. For this purpose, the internal $\mathrm{PO}_{4}^{3-}$ and $\mathrm{HPO}_{4}^{2-}$ ions were randomly chosen. This strategy was maintained for of $1.75 \mu$ s at $350 \mathrm{~K}$ (MD4).

(a)

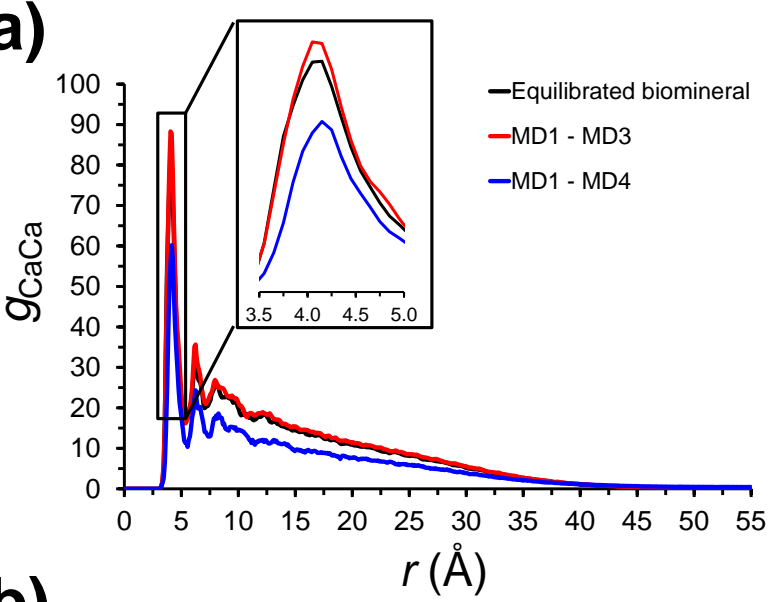

(b)

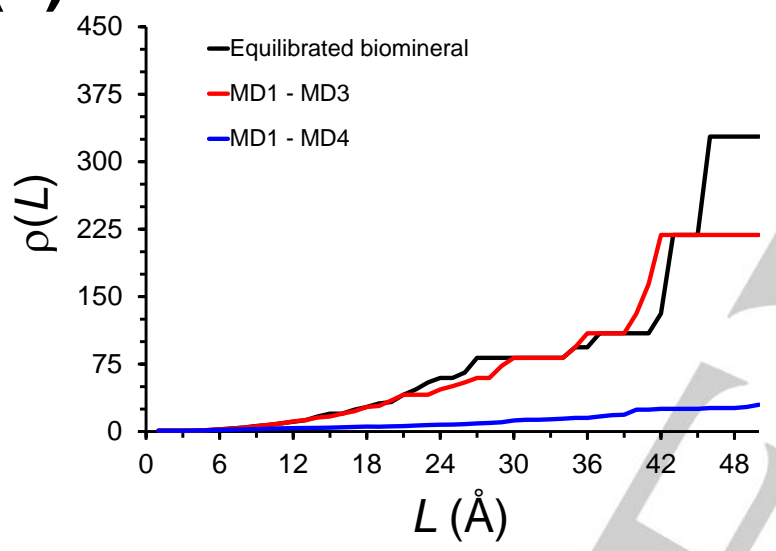

Figure 2. (a) Radial distribution functions of $\mathrm{Ca}^{2+} \ldots \mathrm{Ca}^{2+}$ pairs and (b) $\rho(L)-L$ curves calculated for $\mathrm{HOli}$ after equilibration, three consecutive runs at temperatures increasing from 298 to $350 \mathrm{~K}$ (MD1-MD3), and the latter trajectories plus a run of $1.75 \mu \mathrm{s}$ at $350 \mathrm{~K}$ with proton transfer (MD1-MD4). The inset in (a) evidences the migration of the $\mathrm{Ca}^{2+}$ from the HOli surface to the solution during MD4.

Changes in the $g_{\mathrm{CaCa}}$ and $\rho(L)-L$ profiles after $0.75 \mu \mathrm{s}$ (Figure S3) evidenced that the nanoparticle was dissolving (i.e. $25 \mathrm{Ca}^{2+}$ migrated from the HOli surface to the solution). This dissolution process continued for the next $1 \mu$ s (Figure 2). At the end of MD4, the intensity of the sharp peak at $\sim 4.1 \AA$ in the $g_{\mathrm{CaCa}}$ profile decreased significantly (28\%) with respect to the equilibrated mineral, which was consistent with the drastic reduction of $\rho(L)$ at relatively small $L$ values. The number of $\mathrm{Ca}^{2+}$ that migrated from the nanoparticle to the solution accounted for 144 (i.e. 22\%) after $1.75 \mu \mathrm{s}$ (Figure 1b). In addition, the proton transfer mechanism facilitated the dissolution of $7 \mathrm{Mg}^{2+}(17 \%) 4$ $\mathrm{OH}^{-}(4 \%), 63 \mathrm{PO}_{4}^{3-}(16 \%), 2 \mathrm{HPO}_{4}^{2-}$ and $1 \mathrm{CO}_{3}^{2-}(7 \%)$. This demineralization is dominated by the detachment of $\mathrm{Ca}^{2+}$ from the HOli nanoparticle (i.e. decalcification), the participation of $\mathrm{Mg}^{2+}$ ions in such process being very small at this stage.
Multi-step simulations suggest a decalcification for HOli dissolution, triggered by proton transfer and acid-base based reactivity of the phosphate species. These results are in good agreement with experimental observations on the dissolution of HAp with different acids. ${ }^{[10,18]}$ On the other hand, results reflect a polynuclear detachment of $\mathrm{Ca}^{2+}$ (Figure 3). Although some authors suggested that this mechanism is more probable for HAp dissolution in mild acid environments $(\mathrm{pH}$ within 5.0-7.2 and $\mathrm{Ca} / \mathrm{P}$ molar ratios of $1.0-2.0),{ }^{[19]}$ other authors reported a mononuclear mechanism driven by the formation and growth of pits. ${ }^{[20]}$ Results obtained in this work provide direct evidence that $\mathrm{Ca}^{2+}$ is detached from multiple centers widely distributed on the surface.

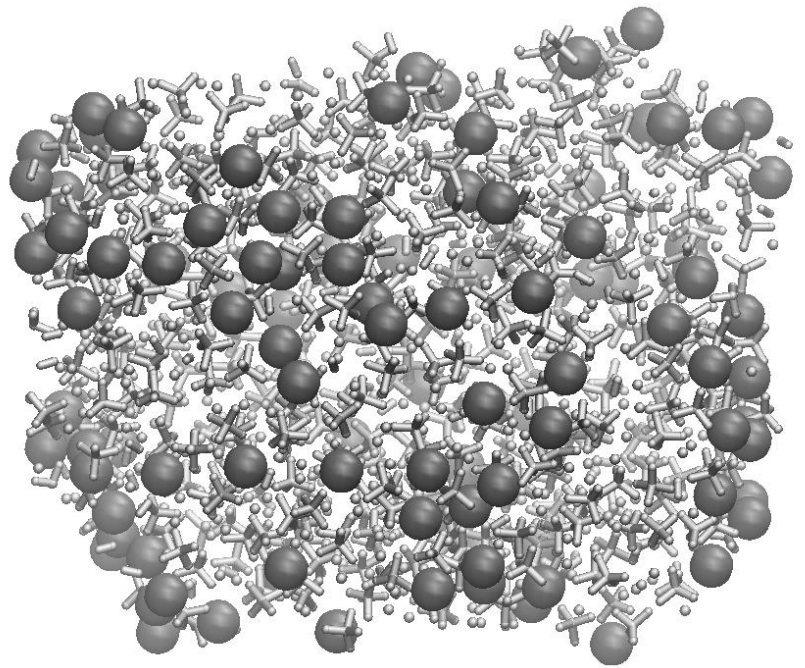

Figure 3. Dissolution of the HOli particle following a polynuclear mechanism. The initial nanoparticle (i.e. starting point for MD1) is displayed. All atoms are depicted with small light grey balls with exception of $\mathrm{Ca}^{2+}$ detached from the surface along MD4 (i.e. the simulation considering proton transfer), which are represented large dark grey balls. As it can be seen, $\mathrm{Ca}^{2+}$ ions detach from multiple centers widely distributed through the surface in the initial configuration. Accordingly, the decalcification process follows a polynuclear mechanism rather than a mononuclear one (i.e. detachment of $\mathrm{Ca}^{2+}$ ions from a few close centers)

On the other hand, results show that $\mathrm{Ca}^{2+}$ mobilitv increases following the transformation of phosphates into $\mathrm{H}_{2} \mathrm{PO}_{4}^{-}$, thus reflecting changes in the coordination caused by the steric and electrostatic components. The latter promotes dissolution of the biomineral (Figure S4). After detachment, $\mathrm{Ca}^{2+}$ preferentially coordinates with two $\mathrm{Cl}^{-}$anions, but also with $\mathrm{OH}^{-}$and $\mathrm{Cl}^{-}$ anions, in hydrated complexes (Figures $4 \mathrm{a}$ and $4 \mathrm{~b}$, respectively). These interactions patterns are supported by the partial radial distribution functions of $\mathrm{Ca}^{2+} \ldots \mathrm{Cl}^{-}\left(g_{\mathrm{CaCl}}\right)$ pairs, which is displayed in Figure $4 \mathrm{c}$. Thus, the $g_{\mathrm{CaCl}}$ profile shows broad and poorly defined peaks centered at $\sim 5.5$ and $\sim 7.0 \AA$ (marked with arrows) that corresponds to the above mentioned complexes. Unfortunately, the partial radial distribution function of $\mathrm{Ca}^{2+} \ldots \mathrm{OH}^{-}\left(g_{\mathrm{CaOH}}\right)$ pairs does not provide any additional information since the distance typically identified in complexes (2.6 $\AA$ in Figure 4b) is very close to the $\mathrm{Ca}^{2+} \ldots \mathrm{OH}^{-}$in the HOli nanoparticle (Figure S5a). Similarly, no relevant information has 
been extracted from the partial radial distribution function of $\mathrm{Ca}^{2+} \ldots \mathrm{H}_{2} \mathrm{O}$ pairs $\left(\left(g_{\mathrm{CaWat}}\right)\right)$ because of the very large number of solvent molecules hydrating $\mathrm{Ca}^{2+}$ ions (Figure $\mathrm{S} 5 \mathrm{~b}$ ).
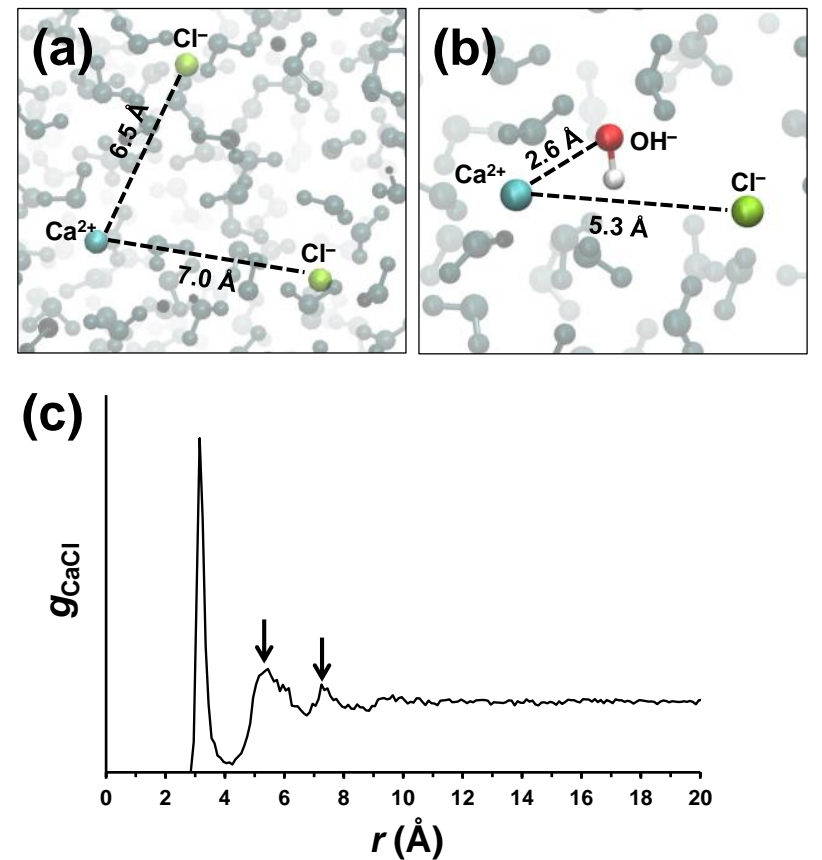

Figure 4. Representative complexes formed by detached $\mathrm{Ca}^{2+}$ ions: (a) detached $\mathrm{Ca}^{2+}$ ions preferentially $(\sim 75 \%$ cases $)$ form hydrated complexes with two $\mathrm{Cl}^{-}$ions; (b) hydrated complexes in which the detached $\mathrm{Ca}^{2+}$ coordinates one $\mathrm{OH}^{-}$and one $\mathrm{Cl}^{-}$are also relatively frequent ( $15 \%$ cases). (c) Radial distribution functions of $\mathrm{Ca}^{2+} \ldots \mathrm{Cl}^{-}$pairs calculated for the last snapshot of MD4. Arrows indicate the distances associated to complexes displayed in (a) and (b).

The structural stability of the ds-DNA can be assessed in Figure 5 which displays the temporal evolution of the root-mean-square deviation (RMSD) with respect to the ideal B-DNA double helix. The RMSD was calculated considering all atoms different from hydrogen. The ds-DNA remains mostly unaltered through the whole range of examined temperatures. The average RMSD calculated for MD1 $(298 \mathrm{~K}), \mathrm{MD} 2(320 \mathrm{~K})$ and MD3 $(350 \mathrm{~K})$ is $0.42 \pm 0.06,1.02 \pm 0.03$ and $1.51 \pm 0.01 \AA$, respectively. The RMSD increases slowly along MD4 as a consequence of the penetration of the protons. In spite of this, the average RMSD for the last $500 \mathrm{~ns}$ of MD4 $(2.03 \pm 0.04 \AA)$ is very low yet. This stability has been attributed to the reduction of the electrostatic strain at the biomolecule associated to the hydrogenated phosphates at the internal regions.

HAp imparts protection against both temperature and chemicals to ds-DNA, which despite its fragility preserves the double helix. During its dissolution, HAp protects totally or partially DNA from physical and chemical stressing factors as well as from the aggression of biological factors, like enzymatic degradation. The HOli NP, which has to be understood as a DNA molecule in its HAp mold, has important implications in many fields. For example, these results are very useful for the development of novel strategies for gene therapy. Thus, biomineralization would facilitate DNA protection by the surrounding inorganic materials, while DNA transported at the surface of the mineral is attacked by endonucleases. ${ }^{[21]}$ From the mass extinction events perspective, we recently discussed the formation and resilience of HOli particles that might made the difference for live surviving. ${ }^{[3]}$ Results from this work also suggests that $\mathrm{HOl}$ particles when dissolving can be also viewed as nanocontainers that store and preserve DNA or RNA from changing environmental conditions, which may have many applications in biomedicine and genetics biotechnology.

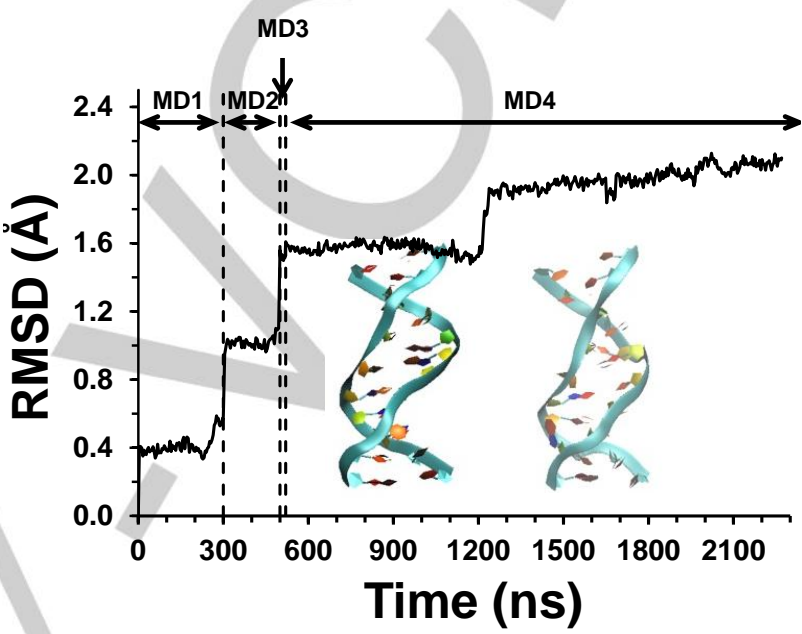

Figure 5. Evolution of the RMSD along the multi-step MD for the ds-DNA relative to the canonical $B-D N A$. The double helix is represented by using a ribbon model for the equilibrated system (starting point of MD1) and for the last snapshot of MD4.

\section{Conclusions}

In conclusion, this work sheds light on the atomic-level details of the acidic dissolution of HOli and HAp. This process happens following a decalcification mechanism where $\mathrm{Ca}^{2+}$ detachment is triggered by the initial hydration of phosphates, and it is enhanced by their further hydrogenation resulting from hydronium reactivity. The decalcification occurs through a polynuclear process: the escape of the calcium ions occurs through multiple independent centers widely distributed on the surface. Thus, the detachment of the calcium ions is caused by the important electrostatic alterations induced by the $\mathrm{HPO}_{4}^{2-}$ and $\mathrm{HPO}_{4}^{2-}$ species rather than by the detachment of neighboring calcium ions. This result has enormous implications for the development of therapies in which fixation of $\mathrm{Ca}^{2+}$ is crucial, as for example those related with the fight against osteoporosis. Also, results prove that HAp acts as a shield for ds-DNA molecules protecting their functionality from temperature stressing conditions and chemicals. Accordingly, HOli particles the represents a very reliable alternative to conventional gene therapy strategies, in which genes are transported at the surface of the mineral and, therefore, undergo the attack of enzymes. 


\section{Experimental Section}

The potential energy was computed using the Amber force-field. ${ }^{[22]}$ Force-field parameters for hydroxyl, $\mathrm{Cl}^{-}$and $\mathrm{PO}_{4}^{3-}$ groups were extracted from Amber ff03. ${ }^{[23]}$ Bondina parameters (i.e. stretching, bending and torsion) for $\mathrm{HPO}_{4}^{2-}$ and $\mathrm{H}_{2} \mathrm{PO}_{4}^{-}$were taken from Homeyer et al., ${ }^{[24]}$ while van der Waals parameter were extracted from Amber ff03. ${ }^{\text {[23] }}$ Atomic charges for the latter two anions were developed in house using the methodology recommended in Amber ff03. ${ }^{[23]}$ Force-field parameters of $\mathrm{Ca}^{2+}, \mathrm{Mg}^{2+}$ and $\mathrm{H}_{3} \mathrm{O}^{+}$were extracted from the work reported by Bradbrook et al., ${ }^{[25]}$ Allner et al. ${ }^{[26]}$, and Baaden et al. ${ }^{[27]}$ respectively. All force-field parameters for DNA were extracted from Amber ff03. ${ }^{[23]}$ It should be noted that the ff03 parameters are identical to the ff99-SB ${ }^{[28]}$ ones for nucleic acids, phosphate and hydroxyl groups. The ability of this set of force-field parameters to reproduce the inorganic...organic interactions found in biominerals was recently proved. ${ }^{[8]}$ The density of water in the simulation box was $1.00 \mathrm{~g} / \mathrm{cm}^{3}$ at a temperature of $298 \mathrm{~K}$. The water molecules were represented using the TIP3P model. ${ }^{[29]}$ All MD simulations were performed using the NAMD 2.6 $6^{[30]}$ code.

Once constructed the initial model (i.e. HOli nanoparticle immersed into an acidic solution) as described in the Results and Discussion subsection the initial simulation box $\left(130 \times 130 \times 130 \AA^{3}\right)$ was equilibrated using the following strategy. Before any of the multi-step MD trajectories, 5000 steps of energy minimization were performed to relax conformational and structural tensions. Next, the system was heated and equilibrated by different consecutive MD runs. First, solvent, $\mathrm{H}_{3} \mathrm{O}^{+}$, and $\mathrm{Cl}^{-}$ions were relaxed and homogeneously distributed in the box by 0.5 ns of NVT (constant volume and temperature) MD at $500 \mathrm{~K}$, while keeping atoms belonging to $\mathrm{HOL}$ (i.e. both HAp components and encapsulated ds-DNA) fixed. After this, thermal equilibration for 0.4 ns in the constant NVT ensemble at $298 \mathrm{~K}$ and a density relaxation for $0.4 \mathrm{~ns}$ in the constant NPT (constant pressure and temperature) ensemble at $298 \mathrm{~K}$ were performed. The last snapshot of the NPT MD was used as the starting point for the first production trajectory, MD1.

MD1 (298 K) is separated from the second production trajectory, MD2 (at $320 \mathrm{~K})$, by a transition NPT trajectory in which the temperature was slowly increased ( $1 \mathrm{~K}$ per $50 \mathrm{ps}$ ). Similarly, MD2 is separated from the third production trajectory, MD3 (at $350 \mathrm{~K}$ ) by a transition NPT trajectory in which the temperature was increased at a rate of $1 \mathrm{~K}$ per $50 \mathrm{ps}$. No transition was needed to evolve from MD3 to the fourth production trajectory, MD4. MD1, MD2, MD3 and MD4 trajectories were 300, 200, 20 and 1750 ns long, respectively, and coordinates saved every 10 (MD1 and MD4), 5 (MD2) or 2 ps (MD3) were used for further analysis. It should be noted that transition trajectories were not considered for the analyses displayed in this work.

In order to ensure the reproducibility of the results, two different initial systems were considered. Accordingly, multi-step MD1-MD4 trajectories were run in duplicate considering different initial positions not onlv for the atoms involved in the HOli nanoparticle but also for the $\mathrm{H}_{2} \mathrm{O}, \mathrm{H}_{3} \mathrm{O}^{+}$and $\mathrm{Cl}^{-}$particles in the acidic solution. Results obtained for the two sets of multi-step MD were very similar and, therefore, only the analyses for one of them are displayed in the figures. The production runs associated to this work involved a total of $(300+200+20+1750) \times 2 \mathrm{~ns}=4.54 \mu \mathrm{s}$

Atom pair distance cut-offs were applied at $16.0 \AA$ to compute the van der Waals interactions. In order to avoid discontinuities in the LennardJones potential, a switch function was applied to allow a continuous decay of the energy when the atom pair distances are larger than $14.0 \AA$. For electrostatic interactions, we computed the non-truncated electrostatic potential throughout Ewald Summations. ${ }^{[31]}$ The real space term was determined by the van der Waals cut-off $(16 \AA)$, while the reciprocal term was estimated by interpolation of the effective charge into a charge mesh with a grid thickness of 5 points per volume unit, i.e. Particle-Mesh Ewald (PME) method. ${ }^{[31]}$ Both temperature and pressure were controlled by the weak coupling method, the Berendsen thermobarostat. ${ }^{[32]}$ The relaxation times used for the coupling were 1 and 10 ps for temperature and pressure, respectively. Bond lengths were constrained using the SHAKE algorithm ${ }^{[33]}$ with a numerical integration step of $1 \mathrm{fs}$. Periodic boundary conditions were applied using the nearest image convention, and the nonbonded pair list was updated every 1000 steps (1 ps).

\section{Acknowledgements}

This work was supported by MINECO-FEDER (MAT201569367-R and MAT2015-69547-R), Generalitat de Catalunya (XRQTC) and B. Braun Surgical S.A. (joint research agreement with UPC). Authors are indebted to the Centre de Supercomputació de Catalunya (CESCA) for computational facilities. This work is integrated within a wider research project supported by B. Braun Surgical S.A., UPC, ICFO and ICS. Support for the research of C.A. was received through the prize "ICREA Academia" for excellence in research funded by the Generalitat de Catalunya.

Keywords: Bioinorganic chemistry; Biomineralization; DNA nanotechnology; Hydroxyapatite; Molecular dynamics

[1] R. F. Cox, A. Hernandez-Santana, S. Ramdass, G. McMahon, J. H. Harmey, M. P. Morgan, Br. J. Cancer 2012, 106, 525-537; C. Jin, P. Frayssinet, R. Pelker, D. Cwirka, B. Hu, A. Vignery, S. C. Eisenbarth, R A. Flavell, Proc. Natl. Acad. Sci. USA 2011, 108, 14867-14872; A. P Sage, Y. Tintut, L. L. Demer, Nat. Rev. Cardiol. 2010, 7, 528-536.

[2] T. Yoneda, K. Hata, M. Nakanishi, M. Nagae, T. Nagayama, H. Wakabayashi, T. Nishisho, T. Sakurai, T. Hiraga, Bone 2011, 48, 100 105; T. D. Tachner, S. Khosla, L. C. Hofbauer, Lancet 2011, 377, 1276 1287.

[3] P. Turon, O. Bertran, J. Puiggalí, C. Alemán, Chem. Eur. J. 2016, 21 18892-18898.

[4] H. Shen, J. Tan, W. M. Saltzman, Nat. Mater. 2004, 3, 569-574; B. Sun M. Yi, C. C. Yacoob, H. T. Nguyen, H. Shen, Acta Biomater. 2012, 8 1109-1116; B. Sun, K. K. Tran, H. Shen, Biomaterials 2009, 30, 63866393

[5] T. Takeshita, Y. Matsuura, S. Arakawa, M. Okamoto, Langmuir 2013 29,11975-11981; S. C. Ngourn, H. A. Butts, A. R. Petty, J. E. Anderson, A. E. Gerdon, Langmuir 2012, 28, 12151-12158.

[6] O. Bertran, L. J. del Valle, G. Revilla, M. Rivas, G. Chaves, M. T. Casas, J. Casanovas, P. Turón, J. Puiggalí, C. Alemán, Chem. Eur. J. 2015, 21, 2537-2546.

[7] O. Bertran, L. J. del Valle, G. Revilla, G. Chaves, LI. Cardús, M. T. Casas, J. Casanovas, P. Turón, J. Puiggalí, C. Alemán, Dalton Trans. 2014, 43, 317-327.

[8] G. Revilla-López, J. Casanovas, O. Bertran, P. Turón, J. Puiggalí, C Alemán, Biointerphases 2013, 8, 10.

[9] L. Wang, G. H. Nancollas, Chem. Rev. 2008, 108, 4628-4669.

[10] S.V. Dorozhkin, World J. Methodol. 2012, 26, 1-17.

[11] R. K. Tang, C. A. Orme, G. H. Nancollas, J. Phys. Chem. B 2003, 107, 10653-10657. 
[12] A. E. Portera, N. Patela, J. N. Skepperb, S. M. Besta, W. Bonfielda, Biomaterials 2003, 24, 4609.

[13] K. Grzeskowiak, D. S. Goodsell, M. Kaczor-Grzeskowiak, D. Cascio, R. E. Dickerson, Biochemistry 1993, 32, 8923-8931.

[14] C. C. Sines, L. McFail-Isom, S. B. Howerton, D. Van Derveer, L. D. Williams, J. Am. Chem. Soc. 2000, 122, 11048-11056.

[15] N. V. Hud, M. Polak, Curr. Opin. Struct. Biol. 2001, 11, 293-301.

[16] R. Kumar, K. H. Prakash, P. Cheang, K. A. Khor, Langmuir 2004, 20, 5196-5200; K. H. Prakash, R. Kumar, C. P. Ooi, P. Cheang, K. A. Khor Langmuir 2006, 23, 11002-11008.

[17] M. Yashima, N. Kubo, K. Omoto, H. Fujimori, K. Fujii, K. Ohoyama, J. Phys. Chem. C 2014, 118, 5180; D. N. Misra, J. Dent. Res. 1996, 75, 1418-1425.

[18] M. Yoshioka, Y. Yoshida S. Inoue, P. Lambrechts, G. Vanherle, Y. Nomura, M. Okazaki, H. Shintani, B. Van Meerbeek, J. Biomed. Mater. Res. 2002, 59, 56-62.

[19] M. R. Christoffersen, J. Dohrup, J. Christoffersen, J. Cryst. Growth 1998, 186, 283-290.

[20] R. K. Tang, C. A. Orme, G. H. Nancollas, J. Phys. Chem. B 2003, 107 , 10653-10657.

[21] L. J. del Valle, O. Bertran, G. Chaves, G. Revilla-López, M. Rivas, M. T. Casas, J. Casanovas, P. Turon, J. Puiggalí, C. Alemán, J. Mater. Chem. B 2014, 2, 6953-6966.

[22] W. D. Cornell, P. Cieplak, C. I. Bayly, I. R. Gould, K. M. Merz, D. M. Ferguson, D. C. Spellmeyer, T. Fox, J. W. Caldwell, P. A. Kollman, J. Am. Chem. Soc. 1995, 117, 5179-5197.

[23] Y. Duan, S. Chowdhury, M. C. Lee, G. Xiong, W. Zhang, R. Yang, P. Cieplak, R. Luo, T. Lee, J. Caldwell, J. Wang, P. A. Kollman, J. Comput. Chem. 2003, 24, 1999-2012.
[24] N. Homeyer, A. H. C. Horn, H. Lanig, H. Sticht, J. Mol. Model. 2006, 12, 281-289.

[25] G. M. Bradbrook, T. Gleichmann, S. J. Harrop, J. Habash, J. Raftery, J. Kalb, J. Yariv, I. H. Hillier, J. R. Helliwell, J. Chem. Soc. Faraday Trans. 1998, 94, 1603-1611.

[26] O. Allnér, L. Nilsson, A. Villa, J. Comput. Theor. Chem. 2012, 8, 1493 1502.

[27] M. Baaden, M. Burgard, G, Wipff, J. Phys. Chem. B 2001, 105, 11131 11141.

[28] V. Hornak, R. Abel, A. Okur, B. Strockbine, A. Roitberg, C. Simmerling Proteins 2006, 65, 712-725.

[29] W. L. Jorgensen, J. Chandrasekhar, J. D. Madura, R. W. Impey, M. L. Klein, J. Chem. Phys. 1983, 79, 926-935.

[30] J. C. Phillips, R. Braun, W. Wang, J. Gumbart, E. Tajkhorshid, E. Villa, C. Chipot, R. D. Skeel, L. Kale, K. Schulten, J. Comput. Chem. 2005 26, 1781-1802.

[31] T. Darden, D. York. L. Pedersen, J. Chem. Phys. 1993, 98, 10089 10092.

[32] H. J. C. Berendsen, J. P. M. Postma, W. F. van Gunsteren, A. DiNola, J. R. Haak, J. Chem. Phys. 1984, 81, 3684-3690.

[33] J. P. Ryckaert, G. Ciccotti, H. J. C. Berendsen, J. Comput. Phys. 1977, 23, 327-341 


\section{Entry for the Table of Contents}

\section{FULL PAPER}

Text for Table of Contents

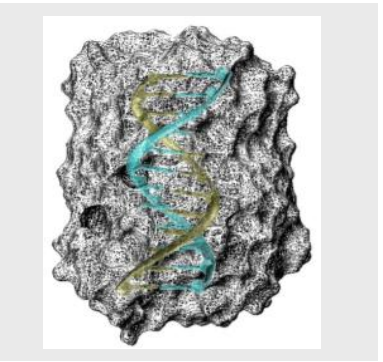

Oscar Bertran, Guillermo Revilla-López, Jordi Casanovas, Luis J. del Valle, Pau Turon, Jordi Puiggalí, * and C. Alemán*

Page No. - Page No.

Dissolving hydroxyolite: A DNA molecule into its hydroxyapatite mold [a] Dr. O. Bertran

Departament de Física Aplicada, EEI, Universitat Politècnica de Catalunya, Av. Pla de la Massa, 8, 08700 Igualada, Spain

[b] Dr. G. Revilla-López, Dr. L. J. del Valle, Prof. Dr. J. Puiggalí, Prof Dr. C. Alemán

Departament d'Enginyeria Química, ETSEIB, Universitat Politècnica de Catalunya, Diagonal 647, 08028 Barcelona, Spain E-mail: jordi.puiggali@upc.edu and carlos.aleman@upc.edu

[c] Dr. J. Casanovas

Departament de Química, EPS, Universitat de Lleida, c/ Jaume II nº 69, Lleida E-25001, Spain

[d] Dr. L. J. del Valle, Prof. Dr. J. Puiggalí, Prof. Dr. C. Alemán Center for Research in Nano-Engineering, Universitat Politècnica de Catalunya, Campus Sud, Edifici C', C/Pasqual i Vila s/n, Barcelona E-08028, Spain

[d] Dr. P. Turon

B. Braun Surgical, S.A. Carretera de Terrasa 121, 08191 Rubí (Barcelona), Spain

E-mail: pau.turon@bbraun.com

Supporting information for this article is given via a link at the end of the document 